\title{
Campesinato, identidade e memória: os tiradores de açaí ou como colocar-se no mundo
}

\section{Peasantry, identity and memory: the tiradores de açaí or how to be in the World}

Sammy Silva Sales - Bacharel em Ciências Sociais pela Universidade Federal do Pará (UFPA); discente do Programa de Pós-Graduação em Ciências Sociais - área Antropologia, Belém-PA. Email: sammy.silva.sales@gmail.com

Noemi Sakiara Miyasaka Porro - Doutora em Antropologia Social pela University of Florida (2002); professora efetiva no Núcleo de Ciências Agrárias e Desenvolvimento Rural/Mestrado em Agricultura Familiar e Desenvolvimento Sustentável da Universidade Federal do Pará (UFPA), Belém-PA. Email: noemip@uol.com.br

\section{Resumo}

Este texto tem como objetivo refletir sobre a intersecção entre os conceitos de campesinato e identidade, a partir do estudo de caso dos tiradores de açaí, chamados de família Monteiro, moradores da vila Monteiro, no município de Afuá (PA). Os dados empíricos coletados através de observação participante e realização de entrevistas foram registrados em 2011 e 2012. Argumentamos que os tiradores de açaí, em situações de reflexão no presente, e por meio de suas práticas, pelas representações sociais e memória coletiva constroem suas identidades sociais coadunadas aos processos sociais em que estão inseridos.

\begin{abstract}
This paper aims think the relation between peasantry and identity concepts as from the case study of tiradores de açaí, called Monteiro family, villagers Monteiro, located in Afuá, state of Pará. The field datas were collected through participant observation and interview in 2011 and 2012. We argue that the tiradores de açaí, in situations of reflection on the present, and through their practices, by social representations and collective memory building their social identities with social processes in which they are inserted.
\end{abstract}

\section{Palavras-chave}

Campesinato. Identidade. Memória. Tiradores de açaí.

\section{Keywords}

Peasantry. Identity. Memory. Tiradores de açaí. 


\section{INTRODUÇÃO}

No meio rural amazônico é possível identificar uma diversidade de grupos sociais imbuídos de dinâmicas sociais, econômicas e culturais específicas, que em processos de transformação interna ou pelos desafios postos por embates com antagonistas externos, exigem a elaboração de respostas capazes de colocá-los enquanto protagonistas nos espaços de disputa.

Além do contexto de mudança em que estão inseridos, outros fatores informam suas práticas e ações sociais, tais como: as relações que estabelecem com outros grupos pelo compartilhamento de experiências e mobilizações para a organização social, com vistas à reivindicação ao acesso e a direitos sociais não garantidos. Essas articulações, entre outras estratégias atualizadas nos processos sociais, são constituintes das diferentes identidades coletivas assumidas e negociadas por diferentes grupos sociais.

O conceito de camponês, ao longo de sua história, no Brasil, tem sido aplicado no estudo de categorias sociais designadas como: trabalhadores rurais, lavradores, agricultores familiares, pequenos produtores e posseiros. Na Amazônia, frente à sua diversidade social, segundo critérios étnicos, a constituição de sujeitos políticos é um elemento presente nas práticas de resistência camponesa, tendo em vista as construções identitárias dos grupos que formam o campesinato amazônico: garimpeiros, peões, pescadores tradicionais, atingidos por barragens, povos da floresta, quebradeiras de coco babaçu, varzeiros, entre outros. Hébette, Magalhães e Maneschy (2002, p. 31) sugerem esquemas de representação em termos identitários e de mobilização política ao campesinato amazônico. Dessa forma, pretendemos delimitar, em termos analíticos, o contexto em que se circunscreve a construção da categoria identitária de grupos sociais extrativistas autodesignados como tiradores de açaí.

A identidade, nos termos de Berger e Luckmann (1976), e enquanto componente de etnicização do campesinato (SEYFERTH, 2011), é formulada e reformulada nos processos sociais, e passível de transformações pelas relações sociais em que se engajam. Na situação empiricamente analisada na Ilha Queimada, na porção ocidental do arquipélago do Marajó, os chamados tiradores de açaí constituem-se e se assumem enquanto tal, tanto no seio de seu próprio grupo social, como também a partir do estabelecimento de relações com diversos atores e mediadores de movimentos sociais e do âmbito acadêmico. Em espaços específicos de representação social, essa identidade se expressa através de outros termos designativos, como ribeirinhos e trabalhadores rurais. Esse exercício de Novos Cadernos NAEA • v. 17 n. 1 • p. 225-240 • jun. 2014 
alteridade pode ser entendido enquanto marco da efetivação do posicionamento político dos tiradores de açaí em espaços públicos de discussão.

Nosso objetivo é refletir a intersecção entre os conceitos de campesinato e identidade a partir do estudo de caso dos tiradores de açaí, uma vez que o empoderamento desse encontro conceitual contribui para a compreensão das transformações e deslocamentos de posições sociais atualmente observadas junto a esse grupo social. Argumentamos que a construção de identidades sociais desse campesinato específico é forjada por meio das práticas materiais e simbólicas, pelas representações sociais e memória coletiva do grupo, no sentido de que em situações de reflexão sobre o presente, a reconstrução da memória está referenciada a quadros histórico-sociais específicos (HALBWACHS, 1990). Assim, o trato metodológico dispensado aos dados empíricos tem em vista interpretar os fatos da memória como percepção da realidade.

A memória coletiva, enquanto fenômeno social, está submetida a flutuações, transformações e mudanças, e os elementos que a constituem são os acontecimentos, personagens e lugares, atribuindo a ela um caráter seletivo e construído (POLLAK, 1992).

Segundo este autor, "A memória é um elemento constituinte do sentimento de identidade" (Idem, p. 204), pois na atualização do tempo passado e das reconstruções de si no presente, os tiradores de açaí se produzem em referência aos outros. Para tanto, utilizamos dados empíricos registrados em trabalho de campo (observação participante e realização de entrevistas com diferentes membros do grupo) junto aos tiradores de açaí, denominados como família Monteiro, moradores da vila Monteiro, município de Afuá (PA) ${ }^{1}$. As atividades de campo em Afuá foram realizadas em dois períodos distintos: primeiramente durante 15 dias no mês de fevereiro de 2011 e, posteriormente, durante 30 dias no mês de janeiro de 2012, sendo que ambos correspondem ao período de safra do açaí nessa região do Marajó. A participação de representantes do grupo dos tiradores de açaí em diferentes eventos do Projeto Procultura (seminários, viagens de intercâmbio, experimentos com extração de óleos) também permitiu observações relevantes.

O trabalho de campo foi realizado no âmbito do Programa Institucional de Iniciação Científica (PIBIC/UFPA) e foi financiado pelo Projeto Procultura (Capes/MinC). Os dados coletados em campo foram utilizados na elaboração do trabalho de conclusão de curso da autora (SALES, 2012). 


\section{CAMPESINATO E IDENTIDADE: UMA DISCUSSÃO}

A constituição histórica do campesinato, muitas vezes, recebe limitada atenção no que tange à percepção e representação pelo próprio grupo. Insistimos que para o entendimento do atual contexto e afirmação da identidade política dos tiradores de açaí, devem-se levar em conta os aspectos relembrados e reafirmados como marcos de transformação, segundo afirmação do próprio grupo: do trabalho pra patrão para o trabalho livre. Se hoje são capazes de perceber as vantagens e desvantagens da anterior e atual condição, valem-se da percepção da sua condição enquanto sujeitos da sua própria história.

O conceito de camponês e de campesinato, enquanto categoria analítica, passou por reelaborações teóricas, resvalando, por vezes, em generalizações que implicavam numa infrutífera homogeneização dos camponeses (SHANIN, 2005). Ainda assim, é inegável a amplitude de significados dos termos camponês e campesinato, e da importância dos inúmeros estudos clássicos sobre o campesinato sob diferentes aspectos, campos empíricos e momentos históricos. $\mathrm{Na}$ perspectiva que tentamos aplicar e interpretar, a análise do campesinato enquanto constituição histórica específica revela fecundos caminhos analíticos (RIBEIRO; FELDMAN-BIANCO, 2003).

Um aspecto do campesinato amazônico, muitas vezes suscitado em estudos como os de Nugent (2002, 2006), Moreira e Hébette (2008) e Schmink e Wood (1992), diz respeito a um modo de viver, produzir e consumir específico e coadunado com o uso dos recursos naturais. Por outro lado, a dinâmica de transformações do espaço rural e de imposições de políticas públicas que ameaçam esse modo de viver, exigem dos grupos camponeses a elaboração de respostas às questões que se sobressaem. Essa dinâmica coloca os tiradores de açaí, enquanto grupo social camponês, em processo de inserção no cenário de representação política. Desse contexto derivam-se algumas dificuldades conceituais.

Os estudos acerca do campesinato amazônico foram impulsionados principalmente pelas transformações sociais decorrentes das ações desenvolvimentistas do governo militar, na década de 1970, pela expansão da fronteira agrícola, pela abertura de estradas como a Transamazônica, com o objetivo de integração da Amazônia ao restante do território nacional, e pelos conflitos sociais e ambientais resultantes das ações empreendidas pelo Estado e pelo capital privado na região, considerada um vazio demográfico (HÉBETTE; MAGALHÃES; MANESCHY, 2002). No entanto, dentre tantas faces do campesinato amazônico, são relevantes também estudos que tratam do

Novos Cadernos NAEA • v. 17 n. 1 • p. 225-240 • jun. 2014 
campesinato das ilhas e dos rios, como sendo um modelo interpretativo do modo de vida de comunidades dispersas ao longo de rios e igarapés, ligadas por laços de parentesco, vizinhança e compadrio, entre as quais se estabelecem relações de trabalho e sociabilidade, e delas extraem a produção para a subsistência e para o mercado (FURTADO, 1993; FURTADO; LEITÃO; MELLO, 1993).

Alguns aspectos sociais e econômicos desse último modelo de campesinato ao qual nos referimos podem ser mais bem elucidados se o pensarmos a partir de um momento específico da história social da Amazônia: a exploração da borracha. Schmink e Wood (1992) e Nugent (2002; 2006) consideram que certas características que persistem até hoje nesse modo de vida específico, são produtos do processo de colonização portuguesa na Amazônia e da herança afro-indígena daqueles que foram a principal força de trabalho nos diferentes períodos de exploração da borracha.

O sistema de regatão e os marreteiros - que funcionavam como rede de comércio entre os grupos dispersos (mão de obra no seringal) e o mercado local (pequenos comerciantes e regatões) - foi a base para a consolidação dos barracões no período de exploração da borracha que, após transformações, ficou conhecido como sistema de aviamento, em que as relações sociais da base da cadeia de fornecimento (e exploração) a crédito eram caracteristicamente personalistas, do tipo patrão-cliente ou patrão-freguês, este último termo usual nas Ilhas do Marajó (SCHMINK; WOOD, 1992).

Apesar de se pensar que, com o colapso do extrativismo da borracha, entrou em crise o sistema de aviamento e de subordinação, o patrão encontrou, por meio de outras formas, manter o domínio sobre a força de trabalho através da exploração de outros produtos da floresta que sustentaram a economia da Amazônia no período da crise da borracha, tal como a madeira, oleaginosas, peles e couros (MARTINELLO, 2004). Nas regiões em que a extração da borracha foi a principal atividade econômica, o sistema social foi um tipo de desdobramento decorrente do sistema comercial implantado pelo comércio da borracha: o sistema de crédito e o "vago sistema de arrendamento de terras" (WAGLEY, 1977, p. 103).

O modo de vida baseado no uso dos recursos da floresta, a caça, a pesca e a roça de subsistência, característicos da herança indígena, permaneceu durante o ciclo da borracha que, segundo Nugent (2006), foi o ponto alto da integração amazônica na economia global. E mesmo após o declínio da produção de látex, deixou como herança "uma versão residual da outrora extensa rede produtiva mercantil” (NUGENT, 2006, p. 38), caracterizada pelo controle do transporte fluvial, cujas embarcações pertenciam a comerciantes que atendiam 
às necessidades básicas de locomoção e de circulação de bens (OLIVEIRA FILHO, 1979, p. 120). Segundo Nugent (2006), a produção da borracha marcou a estrutura econômica da região voltada para a exportação, onde as atividades que os camponeses desempenhavam tinham relação direta com a demanda do mercado.

Ainda que atividades exploratórias de recursos naturais, como a extração de látex e exploração madeireira, revistam-se na figura de um mercado onipresente e coercitivo, muitas comunidades, que décadas depois se identificariam como de tiradores de açaí, consolidaram um modo de vida baseado nas relações de parentesco, amizade e compadrio. Através de suas narrativas, é possível, hoje, identificá-las com características próprias da economia camponesa, regida por uma lógica própria, diferente da capitalista. Essa diferença possibilitaria a sua existência, e seria, ao mesmo tempo, tão necessária quanto a relação direta dos produtores com os mercados local e regional, que sustentam seu modo de viver, produzir e consumir.

Como veremos nos registros da pesquisa empírica, "as marcas" deixadas pela exploração colonial e pela indústria da borracha na estrutura social e econômica do campesinato amazônico não foram conformadas estaticamente no tempo e no espaço. Pelo contrário, entre os tiradores de açaí estão ainda em reconstrução a sua posição e atuação frente às transformações que afetam o seu modo específico de estar e agir no mundo.

A chamada libertação do trabalho para patrão, que ocorreu na década de 1990, e a busca pelos direitos dos tiradores de açaí objetivados nos novos padrões de relação política propiciaram "mudança de posição dos sujeitos de uma existência atomizada para uma existência coletiva" (ALMEIDA, 2008, p. 19). A politização dos termos e designações de uso local e de reconhecimento nacional - a exemplo de "tiradores de açaî" - conformam os agentes sociais em sujeitos da ação "ao adotarem como designação coletiva as denominações pelas quais se autodefinem e são representados na vida cotidiana" (ALMEIDA, 2008, p. 80).

Percebemos os riscos de se utilizar o termo de forma inapropriada; temos investido, portanto, no esforço da pesquisa empírica, participando de ações conjuntas com os tiradores de açaí, e registrando os contextos de afirmação de tal identidade, especialmente no que tange aos processos em curso, de diferenciação desse campesinato, assim como ocorreu com outros grupos: quebradeiras de coco, seringueiros, pescadores artesanais e extrativistas.

O campesinato, portanto, é aqui considerado também como grupo que marca suas diferenças e delineia suas fronteiras com critérios de base étnica, ou seja, uma forma de organização social cujos membros se identificam e são

Novos Cadernos NAEA • v. 17 n. 1 • p. 225-240 • jun. 2014 
identificados como tais pelos outros, devido a critérios elegidos por eles mesmos, dentre aqueles que conformam sua etnicidade (BARTH, 2000).

O conceito de etnicidade e identidade nos auxiliam na compreensão da construção coletiva de identidades políticas. É comumente atribuído à identidade um caráter essencialista sobre o pertencimento e autenticidade de determinado grupo identitário, sendo a identidade outrora vista como fixa e imutável, pela existência de um passado em comum ou cultura material compartilhada. No entanto, a construção de identidades, além de ser forjada pelas condições sociais e materiais, apresenta também um marcador simbólico ante a outras identidades.

Em sua política de identidade, as comunidades tradicionais constituem-se como sujeitos que se apresentam e são reconhecidos como tais e, nesse sentido, são capazes de criar canais de interlocução, visando atender as suas demandas no contexto da sociedade nacional: “[...] alguns grupos camponeses, acionando antigas ou novas etnicidades, conseguiram realizar sua própria 'reforma agrária', restrita, muitas vezes consolidando a posse da terra que já ocupavam" (SEYFERTH, 2011, p. 415).

No escopo da construção de identidades coletivas pelos grupos que se apresentam como povos e comunidades tradicionais - povos indígenas, quilombolas, castanheiros, quebradeiras de coco babaçu, seringueiros, ribeirinhos e demais grupos que constituem o campesinato amazônico - a identidade é incorporada aos discursos de reconhecimento da diversidade cultural e dos fatores étnicos nos processos de disputa e no campo dos conflitos. Assim, cabe salientar o termo "tradicional" como forma de reivindicação de transformações sociais ou como resultado da ação coletiva, portanto, como parte de um processo construído social e politicamente. Almeida (2006a) enfatiza que a tradição

[...] nada tem a ver com permanência e mais se atém a processos reais e sujeitos sociais que transformam dialeticamente suas práticas, mesmo quando as convertem em normas para fins de interlocução, redefinindo suas relações sociais e com a natureza (ALMEIDA, 2006a, p. 11).

O modo de vida tradicional possui raízes no passado, mas a resistência vivida e a renovação cotidiana dessas tradições não exigem um retorno contínuo a uma ancestralidade. A tradição é uma invenção no sentido de consciência de um coletivo e da construção de mecanismos e processos que sustentem a ideia de pertencimento a esse coletivo. Nesse sentido, mesmo aqueles que não exercem a atividade tradicional de trabalho, ainda há, assim, um elemento agregador da identidade como pertencimento à unidade de produção familiar. 
As novas denominações que designam os movimentos e que espelham um conjunto de práticas organizativas traduzem transformações políticas mais profundas na capacidade de mobilização destes grupos face ao poder do Estado e em defesa dos territórios que estão socialmente construindo [...]. Em virtude disto é que se pode dizer que mais do que uma estratégia de discurso tem-se o advento de categorias que se afirmam através de uma existência coletiva, politizando não apenas as nomeações da vida cotidiana, mas também um certo modo de viver e suas práticas rotineiras no uso dos recursos naturais (ALMEIDA, 2008, p. 88-89).

Cabe entender a constituição dos tiradores de açaí enquanto sujeitos coletivos, a partir dos processos concretos em curso. Os tiradores de açaí não possuem, atualmente, embates evidentes com antagonistas externos. No entanto, o processo histórico demonstra que sua dimensão política é resultante dos conflitos anteriores com os antigos patrões, e que os conflitos atuais não estão em evidência. Hoje, na busca por espaços de interlocução, passam pelo processo de expansão das suas redes de relações políticas, tal como participação em eventos, intercâmbios de experiências e conhecimentos com outros grupos sociais, sendo representados pelo Sindicato dos Trabalhadores e Trabalhadoras Rurais (STTR/ Afuá) e pela Associação de Desenvolvimento Intercomunitário do Rio Baiano (ASDICORB), sendo as duas organizações com naturezas de atuação distintas.

Ainda que através da representatividade do sindicato em termos políticos, e da apropriação pelos sujeitos da categoria trabalhador rural na busca pela garantia de certos direitos sociais, permanece um tipo de organização que leva em conta as relações sociais de comunidade, a exemplo das associações que são denominadas segundo o nome dos rios.

Enquanto revestidos da denominação de trabalhadores rurais, em circunstâncias decisórias da categoria ocupacional, mobilizam-se no sentido de garantir sua afirmação e reprodução enquanto camponeses, através do acesso a benefícios específicos a grupos sociais do meio rural. Ao mesmo tempo, veem-se na iminência de impor certa dinamicidade identitária que seja capaz de representá-los em novos espaços.

A interseção entre as categorias campesinato e identidade nos permite lançar um olhar tanto para as relações "externas" de existência desse grupo, quanto relacionada com a maneira pela qual vão estabelecer um equilíbrio com as exigências internas das unidades familiares, especialmente no que diz respeito ao uso das terras tradicionalmente ocupadas. 


\section{CONSTITUIÇÃO SOCIAL DOS TIRADORES DE AÇAÍ: O CASO DA FAMÍLIA MONTEIRO}

A abordagem analítica que empreendemos sobre o processo de mudança social no qual se situam os tiradores de açaí, mostrou-se mais proveitosa quando conjugamos ao esforço interpretativo dessa situação social, a diferenciação social do campesinato. Nesse sentido, Neves (1985) sugere, para evitar o empobrecimento do instrumental analítico, a busca de novas perspectivas para o estudo da diferenciação social, para além da mera análise da desigualdade social. Dessa forma, entende-se a diferenciação social do campesinato como expressão do jogo de forças sociais, com destaque para a participação dos sujeitos enquanto agentes políticos de construção do processo, onde a composição das forças sociais também é diferenciadora.

O enfoque nos indivíduos e a referência a situações empíricas peculiares ou, como neste caso particular, trechos da história de vida da família Monteiro nos fornecem conteúdos refletirmos sobre a constituição identitária desse campesinato, pois o caminho de acesso à memória individual está permeado de informes coletivos dos grupos em que estão inseridos, assim como a formação de lembranças, mesmo que pessoais, explica-se pelas mudanças que se produzem nas relações sociais (HALBWACHS, 1990).

Durante a realização do trabalho de campo, orientei a investigação no sentido de compreender primeiramente a constituição do campesinato das ilhas e dos rios a partir da história de vida da família Monteiro. Minha insistência está presente nas diversas indagações a diferentes membros da família sobre como e quando, afinal, foi a fundação da chamada vila Monteiro, além de detalhes da biografia da família, tais como o ano que Rosemiro e Antônia Monteiro chegaram para viver às margens do rio Preto, a ordem cronológica do nascimento dos filhos e do casamento desses, onde, através desses eventos, entrevemos diferentes momentos da sua constituição. No entanto, além do meu próprio interesse de pesquisa, os sujeitos dessa história interpelam em seus discursos fatos que consideram, naquele contexto de entrevista com a pesquisadora, mais relevantes sobre si mesmos, tal como demonstra José Amorim Monteiro, conhecido por Trevoada, primogênito de Antônia e Rosemiro Monteiro:

[...] eu acho que devia começar [a história] é quando esse terreno aqui era dos Carvalho, era do patrão e nós era freguês [...]. Antes a gente vivia tudo com os pessoal dos Porfírio, que são nossa família aqui de Monteiro e o pessoal dos Porfírio aí em cima, era outra família. Nós trabalhava tudo junto nessa terra, entre o rio Preto e o rio Laranjal [...]. Quando o Zé 
Carvalho veio fazer uma fábrica de palmito aí, aí ele dividiu as área porque ele precisava de um açaizal pra fazer a fábrica de palmito, aí ele dividiu os açaizais pra que nós ficasse, dividiu com o pessoal do Porfírio e nós [...]. Eles trabalhavam na área deles e nós trabalhava na nossa.

A narrativa da formação da Vila Monteiro é marcada pela chegada e estabelecimento de Seu Rosemiro e Dona Antônia Amorim Monteiro no rio Preto, na condição de fregueses nas terras de Zé Carvalho. Este era um patrãocomerciante que recolhia a produção de látex das famílias assentadas por ele em suas terras, assim como de outras áreas do Marajó, e que eram comercializadas na capital, Belém.

As relações estabelecidas entre Zé Carvalho e, posteriormente, por seu herdeiro chamado por Zé Carvalho "filho", e a família de Seu Rosemiro, podem ser caracterizadas pelos papéis desempenhados, respectivamente, enquanto patrão e fregueses no sistema de aviamento. As famílias que eram estabelecidas nos domínios do pretenso dono das terras, e aqueles que para esses trabalhavam, eram chamados de fregueses. Nesse caso particular, tal relação não estava circunscrita apenas a um tipo de relação de trabalho, tinha uma dimensão de parentesco não biológico, visto que Rosemiro era considerado um "filho de criação" de Zé Carvalho, pois quando aquele se tornou órfão, aos 13 anos de idade, foi chamado para trabalhar na embarcação de Zé Carvalho, na função de cozinheiro, e à medida que adquiriu experiência e confiança do patrão, assumiu paulatinamente funções hierarquicamente superiores, até tornar-se encarregado da embarcação de Zé Carvalho. Segundo os entrevistados, tal cargo era de extrema confiança, uma vez que assumia as funções de piloto e era o responsável por todas as negociações nas transações comerciais associadas àquela embarcação. A partir de então, tem início as relações de trabalho de uma vida toda.

Sobre a consciência do regime de trabalho a que estavam submetidos naquele período, não podemos afirmar se possuíam, no entanto, a condição de subordinação patrão-freguês à qual se refere, e na qual permaneceram, é pensada por outros membros da família, como Zenaide Monteiro, da seguinte maneira: "Assim, se fosse como era de primeiro. Eram essas pessoa rica que eram dona das terras, os pobre não tinham terra... Trabalhavam assim na terra, mas não tinham direito nenhum". Tal condição de trabalho é designada localmente como trabalho para patrão.

A condição do trabalho para patrão consistia no controle, por parte do patrão e pretenso dono das terras, sobre o resultado da produção do trabalho familiar, não necessariamente o controle e exploração direta da força de trabalho, pois o emprego da força de trabalho familiar integrava a produção substancial 
dos meios de vida da família sob seu próprio controle (MARTINS, 1990). O elemento característico dessa condição é a ausência da posse da terra pelos fregueses que, através do arrendamento das terras, produziam para o consumo familiar e pagavam a renda para o patrão. Entendemos, pois, que a denominação freguês é relacional - um marcador da diferença entre quem detinha o poder econômico e aqueles subordinados pelo trabalho empregado nas terras do patrão. Como diz Garcia Junior (1983, p. 83), “a categoria patrão supõe sempre que haja uma categoria oposta que designe o trabalhador, qualquer que seja o tipo de trabalhador". No nosso caso, os fregueses. E mesmo estes seriam considerados em melhor situação, se comparados àqueles que sequer tinham um patrão fixo que lhes aviasse o necessário. A efetivação concreta dessa relação era representada pelo pagamento da chamada percentagem, ou seja, uma parte correspondente a $30 \%$ da produção familiar entregue ao patrão na forma de pagamento pelo arrendamento das terras.

O episódio da implantação da fábrica de palmito pelo patrão conformou as áreas de trabalho entre a família Monteiro e a família Porfírio, até a morte de Seu Rosemiro, em 1990, aos 55 anos, decorrente da queda de uma palmeira de açaí, enquanto trabalhava, e a posterior mudança de Dona Antônia para a cidade de Santana (AP). Tais acontecimentos são marcos determinantes no rompimento das relações com o patrão. Após a morte de Seu Rosemiro, a chamada percentagem continuou sendo praticada; e Dona Antônia, enquanto viveu na vila, assumiu a responsabilidade de decisão dos assuntos que envolviam o trabalho da sua família. A sua mudança para Santana (AP), e a transferência da autoridade de decisão e mediação para seu filho Trevoada, foi um momento decisivo:

Aí depois da morte do papai, depois que ele morreu. E aí nós ficamos aí. Depois nós denunciamo a fábrica de palmito, fechou a fábrica, mas aí nós fiquemo nesse mesmo jeito que foi colocado. [...] Só que nós fomos casando [...]. E aí nós trabalhava junto mesmo, ainda. Depois resolvemo dividir [...] nós resolvemo dividir todas as áreas que tocaram pra nós. As áreas todinhas que tocaram pra família do papai nós dividimo com nossos irmão tudo, cada qual pegou uma área, cada qual ficou com uma área. Aí fomo dividindo em vários pedaço porque nós trabalhava lá no centro e trabalhava também no Laranjal, aí nós dividimo lá no centro e lá no Laranjal, pra não ficar um melhor de que o outro, porque nessa época no centro dava mais açaí, no Laranjal dava menos açaí. E então quem fosse ficar no Laranjal, ficava com lugar de roça, mas não ficava com açaizal e dessa época pra cá o açaí melhorou de preço, de venda. Então o intuito mais era em cima do açaí [...] Aí nossos filhos agora foram casando, nós tamo dividindo com eles aí. 
Ainda sob o domínio do patrão, foi realizada a divisão de áreas de trabalho entre os filhos de Rosemiro, como conta Zenaide Monteiro:

Aí ele [Trevoada] dividiu [...] aí dividiu pra cada um, um pedaço de terra. Aí depois que foi dividido, que foi falado pro dono do terreno [...] que ainda andava por aqui e pegava arrendamento das coisa... Era 30 por cento que ele pegava $[\ldots]$ Ih $[. .$.$] muitos anos andando ainda [...] Nós demo$ percentagem até ele morrer, e não faz tantos anos que ele morreu.

Acerca do período do chamado momento da libertação, no final dos anos 1990, quando os então fregueses decidem interromper o pagamento da renda para o patrão, Barbosa (2012) registra a entrada das chamadas geleiras - embarcações que transportam as rasas de açaí no gelo, para serem comercializadas em Belém - como o momento de rompimento das relações de patronagem por parte dos fregueses, pois há uma quebra do monopólio do comércio realizado pelos patrões e, portanto, da sua dominação e exploração. Outro momento é a instalação de outra fábrica de palmito no rio Preto, por Zé Carvalho "filho", que desencadeou uma série de conflitos entre patrão e fregueses, quando aquele colocou outras pessoas para explorar o palmito nas terras arrendadas para os fregueses. Segundo Barbosa (2012, p. 73), “o patrão violou o acordo tácito implícito na relação patrão-freguês do sistema de arrendamento". Concomitantemente, Trevoada, enquanto líder familiar e comunitário, buscou sozinho informações acerca da condição das terras e, consequentemente, dos seus direitos. Através de contatos estabelecidos a partir da sua atuação política no Sindicato de Trabalhadores e Trabalhadoras Rurais (STTR/Afuá), agiu no sentido da extinção do pagamento da percentagem ao patrão.

Sua sobrinha Marlúcia (22 anos), pertencente à terceira geração da família Monteiro, tem registrado na memória a antiga prática e a forma pela qual conseguiram superar a condição de fregueses, como explica:

[...] porque antes era pago a percentagem pro homem, pro dono do terreno. Até um tempo, até quando eu tinha uns 10 anos ainda era pago. [...] Toda viagem que ele vinha tinha que dá uma porção de uns 400, 500 reais [...] Aí ainda tinha o problema que os filhos dele vinham e queriam que pagassem. Aí o tio Zé [Trevoada] conheceu esse movimento do sindicato, aí pronto, o tio Zé disse que não, que ninguém ia pagar mais nada. Aí falavam que eles iam vender o terreno pra outro, era a conversa que falavam: "Ah, se vocês não pagarem, eles vão vender o terreno pra outro". Aí não, eles pagam a nossa indenização e a gente sai, né. Que a gente já trabalhou todos esses anos, desde quando eu nasci, me criei aqui...

A relação de patronagem entre Zé Carvalho e Rosemiro Monteiro, e até mesmo com Zé Carvalho "filho", era diferenciada devido aos laços afetivos 
construídos entre os dois primeiros, o que refletia no tratamento dispensado a toda a família de Rosemiro, mesmo depois de sua morte. Os filhos dele [de Zé Carvalho "filho"] que vinham e queriam que pagassem - que podemos considerar como a nascente terceira geração de patrões - não compartilhavam dos mesmos valores que sustentavam as relações de trabalho entre patrão e freguês

A combinação de acontecimentos no âmbito privado, como o enfraquecimento dos laços de reciprocidade e os processos de participação no âmbito público, que possibilitou o conhecimento dos direitos de permanecer nas terras que trabalharam durante toda a vida, são ilustrativos do processo de libertação do trabalho para patrão. Notamos, também, que a extinção de tal relação de patronagem é relativamente recente - na década de1990 - ao contrário do que achávamos que havia permanecido na época dos barracões da extração da borracha. No entanto, a natureza da relação de patronagem baseada na dominação e exploração não pode ser subsumida, tampouco negligenciada a presença desse tipo de relação na região do rio Baiano e demais localidades do interior de Afuá, e da iminência de conflitos frente às mudanças socioeconômicas que estão ocorrendo, como expõe Dona Verônica (76 anos), uma das fundadoras do STTR/Afuá, sobre um conflito pela terra que resultou no assassinato de Seu Bira, um morador da Ilha do Bode:

[...] a história dele foi bem triste porque eles moravam numa terra que era de um senhor, e ele não queria que eles fizessem nada lá, queria só pra ele a terra. Então eles moravam lá nesse pedaço lá de terra e ele começou a perseguir eles [...] e ele não queria que eles tivesse lá, porque queria que eles vendessem todo o produto pra ele. E sempre foi assim, os patrões, donos dessas terra, só queriam que os ribeirinhos, que moravam naquela terra vendessem tudo pra eles.

Olha, tinha pessoas que levava a borracha, que fazia pra vender, dentro de mala, daquelas mala, daqueles baú, né? Que aqui se chamavam baú, escondido do patrão deles, porque não tinha direito a vender um ovo de galinha, não tinha direito de vender uma borracha pra pegar o dinheiro, era só trocar por mercadoria. E sempre foi assim, os patrões, donos dessas terra, só queriam que os ribeirinhos, que moravam naquela terra, vendessem tudo pra eles.

A realização do trabalho livre é atualmente uma realidade parcial na região do Baiano, pois, se por um lado as lutas encampadas pela regularização da posse da terra e pela efetivação dos direitos dos trabalhadores rurais e dos tiradores de açaí rendem benefícios sociais antes negados a essa categoria, por outro, permanecem famílias que ainda vivem na condição de subordinação aos descendentes dos antigos patrões seringalistas. 


\section{CONSIDERAÇÕES FINAIS}

A categoria social que abriga a designação "tiradores de açấ" contempla, de forma generalizada, aqueles que desempenham cotidianamente, de maneira integrada à unidade de produção familiar, a atividade extrativista de coleta e comercialização do fruto do açaí. Porém, em termos de objetivação identitária, registramos o desempenho dos sujeitos em determinados papéis sociais, como antigos fregueses e peconheiros, cujo diferencial é a consciência do direito que os primeiros têm de acesso e uso do recurso em terras tradicionalmente ocupadas por eles, enquanto os peconheiros trabalham em regime de diárias para os antigos fregueses. Classificações como esta, e tantas outras que emergem das relações sociais, políticas e econômicas em que os tiradores de açaí se inserem, são caras, tanto para o nosso trabalho analítico, quanto para os usos sociais feitos pelo próprio grupo em seus espaços de representatividade, como no sindicato, associação, colônia de pesca e frente ao Estado, através das políticas públicas.

Essa efervescência de posicionamentos dos sujeitos, em termos identitários e ocupacionais, demonstra a força da vivência cotidiana do trabalho nos açaizais, em suas práticas e simbolismos, as possibilidades de colocarem-se no mundo enquanto sujeitos políticos, por meio da atualização da memória recente do grupo, que desempenha também a função de geradora de um conhecimento cujas conceitualizações recobrem parcial e aproximativamente a riqueza de suas experiências. E são justamente nas experiências na dimensão familiar e comunitária, assim como lançar outra luz à imagem do grupo, pintada como a base da mão de obra da política econômica de exploração extrativista impetrada à região, que propusemos o caso dos tiradores de açaí, e do que está por vir a eles, como uma leitura para o atual debate sobre campesinato e identidades na Amazônia.

\section{REFERÊNCIAS}

ALMEIDA, A.W. B. Terra de quilombo, terras indígenas, "babaçuais livre", "castanhais do povo", faxinais e fundos de pasto: terras tradicionalmente ocupadas. 2. ed. Manaus: PGSCA/UFAM, 2008.

ALMEIDA, A.W. B. Identidades, territórios e movimentos sociais na PanAmazônia. In: ACEVEDO MARIN, R.; ALMEIDA, A.W.B. (Orgs.). Populações tradicionais: questões de terra na Pan-Amazônia, Belém: Associação de Universidades Amazônicas, 2006. 
BARBOSA, M. G.“Quem mora em cima da terra é que tem direito!”: o fim da relação freguês-patrão e as novas relações de trabalho na unidade familiar de produção dos chamados "tiradores de açaî" da Vila Monteiro do Rio Preto, no município de Afuá-PA . 2012. 142f. Dissertação (Mestrado em Agriculturas Familiares e Desenvolvimento Sustentável) - Núcleo de Ciências Agrárias e Desenvolvimento Rural, Universidade Federal do Pará, Belém, 2012.

BARTH, F. Os grupos étnicos e suas fronteiras. In: BARTH, F. O guru, o iniciador e outras variações antropológicas. Rio de Janeiro: Contracapa, 2000.

BERGER, P. I.; LUCKMANN, T. A construção social da realidade. Petrópolis: Vozes, 1976.

FURTADO, L. G. Pescadores do rio Amazonas: um estudo antropológico da pesca ribeirinha numa área amazônica. Belém: Museu Paraense Emílio Goeldi, 1993.

FURTAdO, L. G.; LeitÃO, W. M.; MELlo, A. F. de (Orgs.). Povos das águas: realidade e perspectivas na Amazônia. Belém: Museu Paraense Emílio Goeldi, 1993.

GARCIA JÚNIOR, A. Terra de trabalho. Rio de Janeiro: Paz e Terra, 1983. (Coleção Estudos sobre o Nordeste, v.8)

HALBWACHS, M. A memória coletiva. São Paulo: Vértice; Revista dos Tribunais, 1990.

HÉBETTE, J.; MAGALHÃES, S. B.; MANESCHY, M. C. Contemporaneidade do campesinato na Amazônia Oriental. In: No mar, nos rios e na fronteira: faces do campesinato no Pará. Belém: EDUFPA, 2002.

MARTINELLO, P. A "batalha da borracha” na Segunda Guerra Mundial. Rio Branco: EDUFAC, 2004.

MARTINS, J. de S. O cativeiro da terra. 4. ed. São Paulo: Hucitec, 1990.

MOREIRA, E. S.; HÉBET'TE, J. Metamorfoses de um campesinato no Baixo Amazonas e Baixo Xingu paraenses. In: GODOI, E. P.; MENEZES, M. A.; MARIN, R. A. (Orgs.). Diversidade do campesinato: expressões e categorias: construções identitárias e sociabilidades, v.1. São Paulo: UNESP; Brasília, DF: Núcleo de Estudos Agrários e Desenvolvimento Rural, 2008.

NEVES, D. P. Diferenciação sócio-econômica do campesinato. Revista Ciências Sociais Hoje, Anpocs, p. 220-241, 1985. 
NUGENT, S. Whither O campesinato? Historical peasantries of Brazilian Amazonia. Journal of Peasant Studies, v. 29, n. 3, p. 162-189, 2002.

NUGENT, S. Utopias e distopias na paisagem social amazônica. In: ADAMS, C.; MURRIETA, R.; NEVES, W. Sociedades caboclas amazônicas: modernidade e invisibilidade. São Paulo: Annablume, 2006.

OLIVEIRA FILHO, J. P. de. O caboclo e o brabo: notas sobre duas modalidades de força-de-trabalho na expansão da fronteira amazônica no século XIX. In: Encontros com a civilização brasileira. Rio de Janeiro: Civilização Brasileira, 1979.

POLLAK, M. Memória e identidade social. Estudos Históricos, v.5, n.10, 1992. RIBEIRO, G. L.; FELDMAN-BIANCO, B. Antropologia e poder: contribuições de Eric Wolf. Etnográfica, v. 7, n. 2, p. 245-281, 2003.

SHANIN, T. A definição de camponês: conceituações e desconceituações - o velho e o novo em uma discussão marxista. Revista NERA, ano 8, n.7, p. 1-21, jul./dez. 2005.

SCHMINK, M.; WOOD, C. H. Contested frontiers in Amazonia. 2. ed. New York: Columbia University, 1992.

SEYFERTH, G. Campesinato e o Estado no Brasil. Mana, v. 17, n. 2, p. 395-417, 2011.

WAGLEY, C. Uma comunidade amazônica: estudo do homem nos trópicos. Tradução de Clotilde de Souza Costa. 2. ed. São Paulo: Editora Nacional; Brasília: INL, 1977. 